\title{
Destruction of Human Cancers by an Altered Common Cold Virus
}

\author{
Steven B. Oppenheimer
}

$\mathrm{O}$ VER the past decade I have reported in this journal major breakthroughs in cancer research that have been presented in our $\mathrm{Na}$ tional Science Foundation/Howard Hughes Medical Institute-sponsored teacher enhancement programs (Oppenheimer 1987, 1988, 1991, 1995). This paper is a report on what appears to be a new and most promising approach to the future treatment, and perhaps cure, of spread cancer.

Localized cancer is often curable. Spread cancer is what accounts for most cancer deaths (review in Oppenheimer 1995b). The standard conventional treatment for spread cancer is chemotherapy, using an arsenal of chemical agents that kill dividing cells. They kill these cells by interfering with vital processes such as DNA replication and protein synthesis. They affect dividing cells and have little effect on nondividing cells, because dividing cells incorporate these chemical poisons more easily into active biochemical pathways (Oppenheimer 1995b for review).

Chemotherapy can cure some spread cancers, however it often serves as a life extending, not curative, treatment. This is so because chemotherapy also affects normal dividing cells, such as the bone marrow, responsible for producing our immune response. Without an effective immune system, we cannot fight off common pathogens that, once out of control, can easily kill us.

Too much damage to the immune system often occurs before all of the cancer cells are destroyed by chemotherapy. A treatment for spread cancer that targets only cancer cells is desperately needed: a magic bullet.

Exciting things began to happen around 1990 when experimental gene therapy was first used to reverse malignant cell characteristics. Experiments by Bookstein and colleagues (Bookstein et al. 1990) at the University of California, San Diego, found that human prostate cancer cells lost their malignant characteris-

Steven B. Oppenheimer, Ph.D., a Fellow of the American Association for the Advancement of Science, is Professor of Biology and Director of the Center for Cancer and Developmental Biology at California State University, Northridge, Northridge, CA 91330-8303. He is Trustees Outstanding Professor of the 22 campus California State University system. tics when they were inoculated with a specific tumor suppressor gene called RB. The prostate cancer cells possessed defective RB genes. When the normal $R B$ gene was inserted, the prostate cancer cells no longer were able to form tumors in mice.

The story of tumor suppressor genes has been reviewed in this journal and elsewhere (Oppenheimer 1988a, 1988b, 1991, 1995a, 1995b). The experiments by Bookstein's group and others set the stage for use of gene therapy in the future treatment of spread cancer. It is widely believed that cancers in human beings can be reversed by inserting specific tumor suppressor genes into these cancer cells, as it appears that many, if not most, cancers are caused by defective tumor suppressor genes in the first place. The major problem that is currently slowing down progress in this area is the question of delivery. How can tumor suppressor genes be effectively delivered to all cancer cells in the body?

While great optimism abounds for the gene therapy approach for treating cancer, another equally exciting possibility has recently emerged.

For decades we have dreamed of an agent that kills only cancer cells and not normal cells, that can be delivered to cancer cells that are spread around the body. A major breakthrough in this area appears to have been made. Frank McCormick's group at Oxyx Pharmaceuticals in Richmond, California, has used a mutant of the common cold virus that appears to kill many types of cancer cells but not normal cells (Bischoff et al. 1996). Here follows the intriguing story of the virus and how it works.

The tumor suppressor gene p53 (see Oppenheimer 1995a for review) prevents cells from reproducing their own DNA if it has been damaged, or if foreign DNA (such as viral DNA) enters the cell. The gene stops cell division until the damaged DNA is repaired and can initiate cell death if the DNA remains defective. If, however, the p53 gene is itself damaged, cells with altered or foreign DNA can continue to divide, allowing, for example, the preservation of genetic mutations involved in transforming the cells into cancer cells.

More than $50 \%$ of human cancers have defective p53 genes that allow continuous cell division (review in Pennisi 1996). 


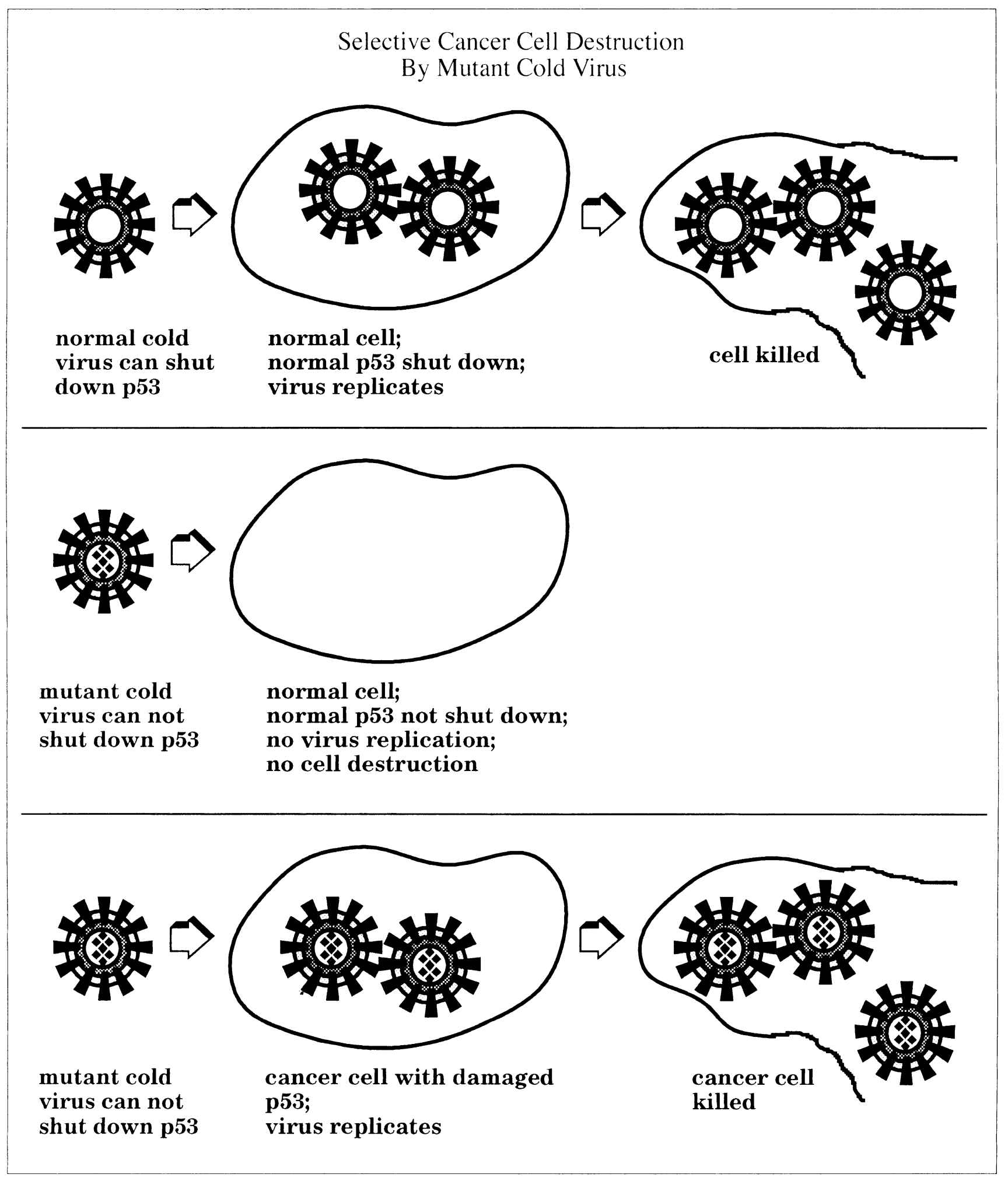

Figure 1. Selective cancer cell destruction by mutant cold virus. The figure depicts how a normal cold virus can replicate in cells by shutting down p53 and how the mutant cold virus, which can not shut down P53, can replicate only in cancer cells with damaged p53.

The common cold adenovirus possesses a stretch of DNA called the E1B region. This region of the viral genome is required for viral replication. It codes for a protein that binds to the protein in cells produced by the p53 gene. That's how the virus can kill cells and, for example, cause the common cold. By inactivating the $p 53$ protein, the $p 53$ gene can no longer block viral DNA replication; hence, the virus multiplies and kills the host cell.

Mutants of the adenovirus were available that either 
lacked the E1B region of the genome or another region that was required for viral reproduction in cells. These mutant viruses could not reproduce in cells with normal p53 genes. However, if the cells lacked a functional p53 gene, the altered virus could replicate in these cells. As indicated earlier, many human cancers lack the functional p53 gene. Thus, an altered virus that cannot inactivate the p53 gene cannot replicate in normal cells possessing functional p53, but can replicate in cancer cells, killing them (Figure 1).

Approximately $50 \%$ of brain cancers, $35-60 \%$ of bladder cancers, $30-40 \%$ of breast cancers, $90 \%$ of virus-caused cervical cancers, $40-70 \%$ of colon cancers, at least $60 \%$ of leukemia, $50 \%$ of lung cancers, $30-35 \%$ of lymphomas, $50 \%$ of melanomas, $40-60 \%$ of ovarian cancers, and $30-60 \%$ of stomach cancers appear to be caused by defective p53 genes (Levine 1996). It is believed that many other human cancers are also caused by defective p53 genes.

McCormick and colleagues found that when the mutant virus was injected into human tumors grown in mice, tumor destruction often occurred. They estimated that only $2 \%$ of the tumor cells needed to be initially infected by the mutant virus to cause tumor destruction, as the other cells in the tumor eventually became infected and destroyed by the spreading virus (Bischoff et al. 1996).

Currently, clinical trials using the mutant virus are taking place in San Antonio, Texas and Glasgow, Scotland. So far, the virus does not appear to cause dangerous side effects, unlike typical chemotherapy (Pennisi 1996).

There are potential problems with this therapy. The human immune system may destroy the virus before its destruction of the cancer cells is complete. Also, the theoretically perfect destruction of cancer cells with defective p53 (but not normal cells possessing functional p53), may not be perfect. Some earlier studies suggest that some cancer cells with defective p53 may not be destroyed by the virus. In human beings, it is

\section{Special Offer for Nonmembers...}

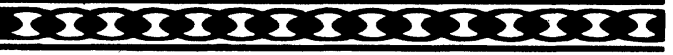

Nonmembers who register for the 1998 Reno meeting can join NABT for one full year and save $\$ 25$ on the nonmember convention registration fee! You receive full admission to the sessions and exhibits plus all the benefits of NABT membership. also possible that normal cells may sometimes become infected by the mutant virus. In addition, there may, in fact, be problems with delivery of the virus to tumor cells spread around the body. So far, most of the work has been done using tumors that can be directly inoculated with virus.

As a scientist myself who has been in this field for more than three decades, even considering the potential problems with this new approach to cancer treatment, I cannot think of a more exciting development with as much potential for cure of spread cancer than this one.

I will provide, free of charge, copies of additional articles in this field, a student research projects handbook, and information on how students can publish the results of their research projects to teachers contacting me by mail on school letterhead.

\section{Acknowledgments}

This article is part of teacher enhancement programs sponsored by the National Science Foundation and Howard Hughes Medical Institute. The Joseph Drown Foundation, National Institutes of Health MBRS and MARC programs, the DOE MAERC program and Thomas Eckstrom Trust also provide support for the author's laboratory. I thank Virginia Latham and Parthenia Hosch for excellent assistance with the art and word processing.

\section{References}

$\rightarrow$ Bischoff, J.R. et al. (1996). An adenovirus mutant that replicates selectively in p53-deficient human tumors. Science, 274, 373-376.

$\rightarrow$ Bookstein, R. et al. (1990). Suppression of tumorigenicity of human prostate carcinoma cells by replacing a mutated RB gene. Science, 247, 712-715.

Levine, A. (1996). National Cancer Institute, Hutchinson Cancer Research Center. Newsweek, December 23, 1996, 45.

$\rightarrow$ Oppenheimer, S.B. (1987). Advances in cancer biology. The American Biology Teacher, 49(1), 11-15.

$\rightarrow$ Oppenheimer, S.B. (1988a). Advances in biological science. The American Biology Teacher, 50(1), 18-22.

Oppenheimer, S.B. (1988b). Antioncogenes. The Science Teacher, 55, 26-27.

$\rightarrow$ Oppenheimer, S.B. (1991). Tumor suppressor genes: A key to the cancer puzzle. The American Biology Teacher, 53(1), 22-24.

$\rightarrow$ Oppenheimer, S.B. (1995a). Discovery of tumor suppressor gene function. The American Biology Teacher, 57(4), 200-201.

Oppenheimer, S.B. (1995b). Cancer, A Biological and Clinical Introduction, 3rd ed. Edina, MN: Burgess International Publishers.

$\rightarrow$ Pennisi, E. (1996). Will a twist of fate lead to a new cancer treatment? Science, 274, 342-343. 